\title{
Revisiting Fungicide-Based Management Guidelines for Leaf Blotch Diseases in Soft Red Winter Wheat
}

K. T. Willyerd, Department of Plant Pathology, The Ohio State University, Ohio Agricultural Research and Development Center (OARDC), Wooster 44691; C. A. Bradley and V. Chapara, Department of Crop Sciences, University of Illinois, Urbana 61801; S. P. Conley, Department of Agronomy, University of Wisconsin, Madison 53706; P. D. Esker, Escuela de Agronomia, Universidad de Costa Rica, San José, Costa Rica; L. V. Madden, Department of Plant Pathology, The Ohio State University, OARDC; K. A. Wise, Department of Botany and Plant Pathology, Purdue University, West Lafayette, IN 47907; and P. A. Paul, Department of Plant Pathology, The Ohio State University, OARDC

\begin{abstract}
Willyerd, K. T., Bradley, C. A., Chapara, V., Conley, S. P., Esker, P. D., Madden, L. V., Wise, K. A., and Paul, P. A. 2015. Revisiting fungicide-based management guidelines for leaf blotch diseases in soft red winter wheat. Plant Dis. 99:1434-1444.

Standard foliar fungicide applications in wheat are usually made between flag leaf emergence (Feekes [FK] 8) and heading (FK10.5) to minimize damage to the flag leaf. However, over the last few years, new fungicide programs such as applications prior to FK8 and split half-rate applications have been implemented, although there are few data pertaining to the efficacy of these programs. Eight experiments were conducted in Illinois, Indiana, Ohio, and Wisconsin from 2010 to 2012 to compare new programs to standard FK8 and FK10 programs in terms of disease control and yield response. The programs evaluated consisted of single full-rate applications of $19 \%$ tebuconazole $+19 \%$ prothioconazole (Prosaro) or $23.6 \%$ pyraclostrobin (Headline) at FK5 (pseudostem strongly erected), FK8, or FK10, or split half rates at FK5 and $8($ FK5+8), plus an untreated check $(\mathrm{CK})$. Leaf blotch (LB) severity and yield data were collected and random effects meta-analytical models fitted to estimate the overall log odds ratio of disease reaching the flag leaf $\left(\bar{L}_{O R}\right)$ and mean yield increase $(\bar{D})$ for each fungicide program relative to CK. For all programs, $\bar{L}_{O R}$ was significantly different from zero $(P<0.05)$. Based on estimated odds

reaching the flag leaf by 55 and $75 \%$, compared with 62 and $69 \%$ and 67 and $70 \%$ for the two FK10 and FK5+8 programs, respectively, and only 32 and $37 \%$ for the two FK5 programs. $\bar{D}$ was significantly different from zero $(P \leq 0.003)$ for all FK8, FK10, and FK5 +8 programs, with values of 233 and 245, 175 and 220, and 175 and $187 \mathrm{~kg} \mathrm{ha}^{-1}$ for the FK10, FK5+8, and FK8 programs, respectively. Differences in mean yield response between Headline and Prosaro were not statistically significant $(P>0.05)$. The probability of profitability was estimated for each program for a range of grain prices and fungicide application costs. All FK8, FK10, and FK5+8 programs had more than an $80 \%$ chance of resulting in a positive yield response, compared with 63 and $67 \%$ for the two FK5 programs. The chance of obtaining a yield increase of $200 \mathrm{~kg} \mathrm{ha}^{-1}$, required to offset an application cost of $\$ 36 \mathrm{ha}^{-1}$ at a grain price of $\$ 0.18 \mathrm{~kg}^{-1}$, ranged from 44 to $60 \%$ for FK8, FK10 and FK5+8 programs compared with 22 and $25 \%$ for the two FK5 programs. These findings could be used to help inform fungicide application decisions for LB diseases in soft red winter wheat.
\end{abstract} ratios $\left(\mathrm{OR}=\exp \left[\bar{L}_{O R}\right]\right)$, the two FK8 programs reduced the risk of LB
In the United States, soft red winter wheat (SRWW) is grown predominantly in states east of the Mississippi River, including Indiana, Wisconsin, Illinois, and Ohio, with the latter two states being among the top four producers of SRWW in the country. Although most of the modern cultivars grown in the region have the potential to yield more than the 2013-14 average of 4.29 metric tons [MT]/ha, warm growing conditions usually reduce productivity by shortening the grain-fill period (Barker et al. 2005). In addition, foliar diseases such as Septoria leaf blotch (Septoria tritici), Stagonospora leaf blotch (SLB) (Parastagonospora nodorum), tan spot (Pyrenophora tritici-repentis), leaf rust (Puccinia triticina), and powdery mildew (Blumeria graminis) may substantially reduce yield in some seasons (Bhathal et al. 2003; Lackermann et al. 2011). Flag leaf damage is of particular concern because the health of this leaf is often associated with kernel development, grain weight, and yield (Ruske et al. 2003; Simpson 1968). Models have shown that the greatest contributors of photoassimilates for grain-fill are the blade (45\%) and sheath (25\%) of the flag leaf and the glumes of the spike (25\%), whereas the leaf below the flag leaf accounts for less than $5 \%$ of the total carbohydrates in the grain (Lupton 1972).

Corresponding author: P. A. Paul; E-mail: paul.661@osu.edu

Any opinions, findings, conclusions, or recommendations expressed in this publication are those of the authors and do not necessarily reflect the view of the United States Department of Agriculture.

Accepted for publication 16 March 2015.

http://dx.doi.org/10.1094/PDIS-02-15-0218-RE

(C) 2015 The American Phytopathological Society
To minimize grain yield and quality losses caused by diseases, integrated disease management (IDM) programs are designed to protect the flag leaf and the spike. Host resistance, cultural practices, and chemical control strategies are often combined to reduce inoculum build-up, infection, and disease development (Milus and Chalkley 1997). Under current IDM guidelines, foliar fungicide applications are based on crop growth stage and disease thresholds (Bowden 1995; Heger et al. 2003; Paveley et al. 1997), and are commonly recommended only when susceptible cultivars are planted. For instance, fungicides are usually applied at flag leaf emergence (Feekes 8) or at the boot stage (Feekes 10) (Large 1954) for management of leaf blotching diseases such as SLB, Septoria tritici blotch, and tan spot, using disease severity on the flag leaf and the leaf below the flag leaf as thresholds for decision making (Barker et al. 2005; Bowden 1995).

Based on years of foliar fungicide trials in hard red winter wheat (HRWW) in Kansas, Bowden (1995) suggested that foliar disease potential should be used as a guide to estimate yield responses to fungicides, stating that, when disease levels are low, moderate, and high, expected yield increases to fungicides can be estimated at approximately 5, 10, and $15 \%$, respectively. Results from studies conducted at other locations showed that there was indeed an association between yield response to fungicides and baseline foliar disease levels. For instance, Lopez et al. (2015) and Wegulo et al. (2012) observed modest or no yield response to fungicides in Texas and Nebraska, respectively, in years with low disease levels, whereas Ransom and McMullen (2008) and Thompson et al. (2014) found that significant yield increases in response to fungicides were frequently associated with high disease levels in HRWW in North Dakota and Oklahoma, respectively. Similarly, Weisz et al. (2011) showed that, in environments with low levels of foliar disease, the average yield response to 
foliar fungicides was not high enough to cover application cost in SRWW in the Mid-Atlantic region. On average, fungicide-treated fields tend to yield up to $20 \%$ more than nontreated fields when leaf blotching disease levels are high (Bergstrom 2010).

However, over the last few years, SRWW producers have increasingly resorted to prophylactic use of fungicides. There are several reasons for this practice, including the availability of more effective and less expensive fungicides that may affect crop physiology, an increase in cultivars with high yield potential, and higher grain prices. The use of foliar fungicides as "insurance" is not novel in agriculture but claims of physiological benefits in response to fungicides in the absence (or at low levels) of disease have contributed to this practice becoming more widespread over the last decade. Physiological benefits are often associated with the quinone outside inhibitor (QoI) fungicides, and justifications given for prophylactic applications rather than following IDM guidelines include control of secondary diseases, reduction of respiration-associated losses, and extension of the green leaf area duration of treated plants (Grossmann et al. 1999; Pepler et al. 2005; Ruske et al. 2003; Wu and von Tiedemann 2001). However, most of these claims have not been substantiated by data from field experiments.

Other recent trends in prophylactic fungicide use include applications at or prior to the flag leaf emergence growth stage (Feekes 8) and split applications, with half the label-recommended rate at or before jointing (Feekes 6) followed by a second half rate at or after Feekes 8 . The rationale behind these trends is based in part on the fact that foliar fungal diseases such as SLB and Septoria leaf blotch may become established in the fall, overwinter as asymptomatic infections on the host, and resume development on lower leaves in early spring (Bergstrom 2010; Shaner 2010; Shaner and Buechley 1995). Spores produced on lower leaves spread and cause secondary infections on upper plant parts (Shaner and Buechley 1995) that are important for grain development (Lupton 1972). Pesticide application-related costs such as fuel prices and yield loss caused by wheel track damage (Weisz et al. 2011) are also given as justifications for early fungicide applications. In order to minimize these costs, fungicides, herbicides, and fertilizers are often tank-mixed and applied at or before jointing to reduce the number of application passes across a field (Wegulo et al. 2012). Wheat is more likely to compensate for and recover from damage caused by a single set of wheel tracks made before jointing than tracks made at or after Feekes 8 (Weisz et al. 2011).

Although foliar diseases during early developmental stages of the wheat plant may affect grain yield (Shaner and Buechley 1995), and damage to plants during application may result in yield loss (Weisz et al. 2011; Thompson et al. 2014), there is little research-based evidence to support or discourage early or split fungicide applications. The disease management and economic value of these practices are largely unknown. Therefore, the ultimate goal of this research was to reevaluate and redefine foliar fungicide application guidelines for SRWW based on disease and yield responses to modern fungicides and cultivars. The specific objective of the research presented here was to evaluate the efficacy and profitability of different fungicide-based programs for managing leaf blotch (LB) diseases of wheat in the Great Lakes region of the United States. The programs evaluated consisted of QoI and demethylation inhibitor (DMI) fungicides applied at half or full rates between Feekes 5 and 10 to SLB-susceptible and -resistant cultivars. Parastagonospora nodorum-inoculated experiments were conducted under different environmental conditions to formally examine the popular belief that applications prior to Feekes 8 and split applications provide disease control and yield benefits comparable with or greater than that of standard Feekes 8 and 10 applications, and that yield benefits are greater with QoI than DMI fungicides. Additionally, a cost-benefit analysis was performed to evaluate the profitability of the fungicide programs for a range of fungicide application costs and grain prices.

\section{Materials and Methods}

Plot establishment. Uniform field experiments were established from 2010 to 2012 at the University of Illinois Crop Sciences
Research and Education Center near Urbana (IL10, IL11, and IL12); Southwest Purdue Agricultural Center, Vincennes, IN (IN10, IN11, and IN12); Ohio Agricultural Research and Development Center Snyder Farm near Wooster (OH10 and OH11); and University of Wisconsin Arlington Research Station, Arlington (WI10 and WI11). In all but one experiment (IL10), the experimental design was a randomized complete block, with three replications and a split-split-plot arrangement of cultivar (whole plot), fungicide treatment (subplot), and inoculation treatment (sub-subplot). In IL10, there were four replicate blocks, with cultivar as whole plot and a factorial arrangement of fungicide and inoculation treatments as subplot.

Plots of SRWW 'Pioneer 25R39' (moderately susceptible to SLB and moderately resistant to Fusarium head blight [FHB, caused by Fusarium graminearium] and moderately susceptible to powdery mildew [caused by Blumeria graminis]) and 'Dyna Gro 9911' (Illinois, Indiana, and Wisconsin) or 'Dyna Gro 9922' (Ohio) (both moderately resistant to SLB, FHB, and powdery mildew) of similar maturity and yield potential (Beuerlein et al. 2010) were planted on 21 October 2009, 8 October 2010, and 11 October 2011 in Illinois; 1 October 2009, 27 September 2010, and 25 October 2011 in Indiana; 6 October 2009 and 1 October 2010 in Ohio; and 30 September 2009 and 27 September 2010 in Wisconsin. In Ohio, each plot consisted of seven 6-m-length rows, spaced $0.19 \mathrm{~m}$ apart ( $1.5 \mathrm{~m}$ wide) and planted with a Kincaid planter at a seeding rate of $4 \times 10^{6}$ seeds $\mathrm{ha}^{-1}$. In Illinois, plots were 1.5 by $6 \mathrm{~m}$ and planted with a Great Plains no-till drill (3P606NT) at a seeding rate of approximately $3 \times 10^{6}$ seeds $\mathrm{ha}^{-1}$. Plots in Wisconsin were $2.4 \mathrm{~m}$ wide $(0.19-\mathrm{m}$ row spacing) by $7.6 \mathrm{~m}$ long and seeded at $3.7 \times 10^{6}$ seeds ha ${ }^{-1}$, with seven center harvest rows and two nonharvest border rows, using a grain drill with cone units. In Indiana, plots of 1.6 by $6 \mathrm{~m}$ were planted at a row spacing of $0.19 \mathrm{~m}$ with a Great Plains no-till drill at a seeding rates of $4.5 \times 10^{6}$ seeds $\mathrm{ha}^{-1}$. Plots were managed and fertilizers and pesticides were applied according to standard agronomic practices for each location (Barker et al. 2005; Conley et al. 2014; Mansfield and Hawkins 1992; Nafziger 2009; Paul et al. 2008a).

Fungicide programs. Nine fungicide programs were evaluated, consisting of two fungicides with different modes of action, each with a single application at one of three growth stages, or a splitapplication at two different growth stages, plus an untreated control. The programs were the DMI fungicide Prosaro 421 SC (19\% tebuconazole $+19 \%$ prothioconazole; Bayer CropScience, Research Triangle Park, NC) applied at Feekes 5, 8, or 10 at the full rate recommended by the manufacturer $\left(100 \mathrm{~g}\right.$ of each a.i. $\left.\mathrm{ha}^{-1}\right)$, or at split half rates applied at Feekes 5 and 8 (PFULL5, PFULL8, PFULL10, and PHLF5+8); and the QoI fungicide Headline (23.6\% pyraclostrobin; BASF Corporation, Research Triangle Park, NC), also applied at Feekes 5, 8, or 10 at the recommended rate $\left(110 \mathrm{~g}\right.$ a.i. $\left.\mathrm{ha}^{-1}\right)$, as well as split half rates at Feekes 5 and 8 (HFULL5, HFULL8, HFULL10, and HHLF5+8). The untreated check was included in each experiment as the reference against which all other treatments were compared.

All fungicide treatments included $0.125 \%$ of a nonionized surfactant (Induce; Helena Chem. Company, Collierville, TN), and applications in Ohio were made using either a tractor-mounted or backpack (R\&D Sprayers, Opelousas, LA) sprayer, with booms fitted with XR8001 nozzles (TeeJet Technologies, Dillsburg, PA), and calibrated to apply at a rate of 187 liters ha ${ }^{-1}$ at a spray pressure of $207 \mathrm{kPa}$. In Illinois, applications were made using a $\mathrm{CO}_{2}$-pressurized backpack sprayer and handheld boom, equipped with three TwinJet XR8002 nozzles, at a rate of 187 liters ha ${ }^{-1}$ at $276 \mathrm{kPa}$; whereas, in Indiana, treatments were applied with a $\mathrm{CO}_{2}$-pressurized backpack sprayer and a hand-held boom fitted with single TJ8001VS nozzles calibrated to deliver 187 liters ha $^{-1}$ at $276 \mathrm{kPa}$. In Wisconsin, treatments were applied using XR 8003 Flat Fan nozzles at 187 liters ha $^{-1}$ at $207 \mathrm{kPa}$.

Inoculum preparation and inoculation. Inoculation treatments consisted of a spore suspension spray applied at Feekes 6 or Feekes 9, plus a noninoculated control. Spore suspensions were prepared using $P$. nodorum pycnidiospores from multiple isolates collected locally in each state from diseased wheat leaves. In all cases, these isolates were used to seed V8 media, and cultures were incubated at room temperature under a 12-h diurnal cycle of white and near 
UV lights for 7 to 10 days. After incubation, pycnidiospores were used to seed new V8 or potato dextrose agar plates. Following an additional 7 to 10 days of incubation under conditions similar to those described above, spores were harvested by flooding plates with sterile water, scraping the agar with a sterile glass rod or rubber policeman, and filtering the suspension through sterile cheesecloth. The resulting spore suspensions were stored at $-20^{\circ} \mathrm{C}$ until used for inoculation.

At the time of inoculation, stock spore suspensions were thawed at room temperature and diluted to $5 \times 10^{5}$ spores $\mathrm{ml}^{-1}$ (in 2010) and $10 \times 10^{5}$ spores $\mathrm{ml}^{-1}$ (in 2011 and 2012) using sterile distilled water. Tween 20 (polyoxyethylene-sorbintan monolaurate; Sigma-Aldrich, St. Louis) was then added to each suspension at a rate of $0.01 \%$ (vol/vol). In Ohio, inoculum was applied using $\mathrm{CO}_{2}$-pressurized backpack sprayers (R\&D Sprayers) equipped with a 1.2-m-long boom with three Turbo Teejet Induction flat spray tips calibrated to spray at a rate of 220 liters $\mathrm{ha}^{-1}$ (at $207 \mathrm{kPa}$ ). In Indiana, inoculum was also applied with a $\mathrm{CO}_{2}$-pressurized backpack sprayer and a handheld boom fitted with four TJ8002VS nozzles calibrated to deliver 237.4 liters $\mathrm{ha}^{-1}$ at $275.8 \mathrm{kPa}$, with each plot receiving approximately $300 \mathrm{ml}$ of the spore suspension. Inoculation protocols very similar to those used in Ohio and Indiana were used in Illinois and Wisconsin.

Data collection and analysis. Disease assessment and grain yield. LB ratings commenced when symptoms were first detected on the lower leaves in the untreated susceptible check plots. This occurred between Feekes 8 and 10, depending on the environment, and ratings generally continued weekly until Feekes 10.5 .4 or 11.1, growth stages at which lesions had progressed up the canopy to the flag leaf but symptoms were still easily distinguishable from natural senescence. Our initial intent was to focus on SLB (hence the inoculations with $P$. nodorum) but, at the time of disease assessment, lesions of Septoria leaf blotch (caused by $S$. tritici) resulting from natural infection were also observed in some environments. Because it is not always easy to distinguish among leaf blotching diseases in the field (Bergstrom 2010; McMullen 2010; Shaner 2010) and it is often impractical to rate them separately, we rated total LB severity. For most locations and years, severity of LB was estimated using a 0-to-10 leaf-position-dependent assessment scale, which gave weight to both disease severity (percent diseased leaf area) on each of the top four leaves and the height (vertical position) of the diseased leaf within the canopy (Table 1) (Lipps and Madden 1989). The scale is essentially based on the severity of the highest leaf visibly diseased. Lipps and Madden (1989) showed that yield of wheat is directly proportional to severity of powdery mildew using this scale. For trials conducted in Illinois in 2011 and 2012, disease severity was assessed

Table 1. Leaf position-dependent severity rating scale for leaf blotch (LB) diseases of wheat ${ }^{\mathrm{a}}$

\begin{tabular}{llcc}
\hline Class & Leaf & Severity & New class \\
\hline 0 & Any & $0 \%$ & 0 \\
1 & 4th & 1 to $50 \%$ & 0 \\
2 & 3rd & 1 to $5 \%$ & 0 \\
3 & 3rd & 5 to $15 \%$ & 0 \\
4 & 3rd & $>15 \%$ & 0 \\
5 & 2nd & 1 to $5 \%$ & 0 \\
6 & 2nd & 5 to $15 \%$ & 1 \\
7 & 2nd & $>15 \%$ & 1 \\
8 & Flag & 1 to $5 \%$ & 2 \\
9 & Flag & 5 to $15 \%$ & 2 \\
10 & Flag & $>15 \%$ & 2 \\
\hline
\end{tabular}

${ }^{a}$ Flag = flag leaf, the uppermost leaf of the wheat plant; and 2nd, 3rd, and 4 th $=$ first, second, and third leaves, respectively, below the flag leaf. Severity = percent leaf area covered with LB (Stagonospora leaf blotch, Septoria leaf blotch, or tan spot) lesions. New class = LB severity classes, with 0 representing low LB severity, $<5 \%$ severity on the second leaf; 1 representing moderate severity, $\geq 5 \%$ severity on the second leaf but not on the flag leaf; and 2 representing high severity, corresponding to any level of LB on the flag leaf. Scale adapted from Lipps and Madden (1989). on the flag leaf only. Other common wheat diseases such as glume blotch and FHB were also rated, when present. All disease assessments were made on 5 to 10 arbitrarily selected tillers or clusters of tillers per sub-subplot.

Plots were harvested between the last week of June and the last week of July, depending on the location and year, using research plot combines. Yield data were adjusted to $15.5 \%$ moisture, then combined with final LB severity data (for assessments made between Feekes 10.5.4 and 11.1) and used as the dependent variables for data analysis.

Fungicide program and cultivar effect on $L B$ severity. For data analysis, each combination of location (Illinois, Indiana, Ohio, and Wisconsin) and year (2010, 2011, and 2012) was treated as a separate environment (heretofore referred to as environments). Experiments in Indiana and Ohio in 2011 were lost due to flooding and freezing, respectively. In IL12 and IN12, early fungicide and inoculation treatments were not applied. For all environments, LB severity (0-to-10 scale for IL10, IN10, OH10, WI10, WI11, and IN12, and percent flag leaf area diseased for IL11 and IL12) was analyzed with nonparametric marginal-effects analysis (Brunner et al. 2002; Shah and Madden 2004). This analysis based on ranks estimated the main effects of fungicide program, cultivar, and SLB inoculation, and all two-way and the three-way interactions on the normalized distribution functions. The block effect was removed by ranking observations within each block (Gao 2007). A compound symmetry variance-covariance structure was used within each whole plot, and separate variances and covariances were specified for each whole plot. All analyses were done with the MIXED procedure in SAS (Littell et al. 2006), utilizing the ANOVAF option. Multiple comparison of mean ranks was done with the PLM procedure using stored results from the MIXED procedure.

Fungicide program effect on the risk to $L B$ reaching the flag leaf. In addition to the effects of fungicide treatments on whole-plant and plot-level disease severity, it is often of interest to more specifically assess their effects on the risk of disease reaching the flag leaf (or conversely, being restricted to leaves below the flag leaf). For the purpose of this analysis, the 11-class severity scale was compressed to a 3-class scale (Table 1), representing LB at different positions within the wheat canopy. Feekes 10.5 .4 to 11.1 severity scores for all samples (5 to 10 per sub-subplot) were recategorized into one of three new severity classes: $0=$ low LB severity, corresponding to $<5 \%$ severity on leaf 2 (categories 0 to 5 on the original scale); $1=$ moderate severity, corresponding to severity $\geq 5 \%$ on leaf 2 but not on the flag leaf (categories 6 and 7 on the original scale); and 2 = high severity, corresponding to any level of LB on the flag leaf (categories 8, 9, and 10 on the original scale).

For reasons discussed at length elsewhere (Gbur et al. 2012; Shah and Madden 2004; Stroup 2013), and based on the fact that the specific question being addressed here pertains to the odds or likelihood of LB reaching a certain position within the wheat canopy, a generalized linear mixed-modeling (GLMM) approach was used for this analysis. For each environment and cultivar combination (considered here as separate studies), the proportional odds model was fitted using the GLIMMIX procedure of SAS to estimate the odds of LB being assigned to severity classes 0,1 , or 2 , as influenced by fungicide program. Because nonparametric analyses of the data showed that the two- and three-way interaction effects involving inoculation and cultivar on LB severity were generally not statistically significant (see Results), these two factors were suppressed for GLMM analysis. Proportional odds models were fitted using the cumulative logit link function $(\eta)$ of LB severity class, with the distribution specified as multinomial. The model can be written as:

$$
\begin{aligned}
& \eta_{0 j k}=\log \left(\frac{\pi_{0 j k}}{1-\pi_{0 j k}}\right)=\theta_{0}+\beta_{j}+b_{k} \\
& \eta_{l j k}=\log \left(\frac{\pi_{0 j k}+\pi_{l j k}}{1-\left(\pi_{0 j k}+\pi_{l j k}\right)}\right)=\theta_{1}+\beta_{j}+b_{k}
\end{aligned}
$$

where $\log (\bullet)$ is the natural $\log \operatorname{link}$ function, $\pi_{\bullet j k}$ is the probability of LB falling into a certain severity category (reaching a certain 
position within the canopy) for the $j$ th treatment in the $k t h$ block. $\beta_{j}$ is the effect of the $j$ th treatment on $\eta, b_{k}$ is the effect of the $k$ th block, and $\theta_{0}$ is an intercept term for each equation (which gives the transition between the classes). In particular, $\pi_{0 j k}$ is the probability of severity class $0(<5 \%$ disease on the second leaf $)$, and $\pi_{\bullet l k}$ is the probability of a leaf being in new severity class 1 ( $\geq 5 \%$ severity on leaf 2 but no flag leaf disease); $\pi_{\bullet 2 k}$, the probability of any disease on the flag leaf, is determined from $1-\pi_{0 j k}-\pi_{l j k}$. After fitting the models with GLIMMIX, the estimate statement was used to estimate the log odds ratio $\left(L_{O R}\right)$ for each fungicide treatment, which is the same as the difference of log odds between each treatment and the untreated check.

Estimated $L_{O R}$ values and their standard errors from each environment-cultivar combination were combined, and separate univariate random-effects meta-analytical models were fitted for each fungicide program, as described by Borenstein et al. (2009), to estimate overall log odds ratios $\left(\bar{L}_{O R}\right)$ and their $95 \%$ confidence intervals (CI) across all studies. For this meta-analysis, fixed within-study weights were determined as the inverse of the square of the standard errors of $L_{O R}$; models were fitted in PROC MIXED of SAS using restricted maximum likelihood, and the significance of $\bar{L}_{O R}$ was determined with a standard normal test, as previously described (Madden and Paul 2011; van Houwelingen et al. 2002). For each fungicide program, the overall odds ratio (OR) across experiments and the upper and lower limits of the $95 \%$ CI around OR were then estimated by back-transforming the mean effect size and the limits of its confidence interval as $\exp \left(\bar{L}_{O R}\right)$.

Odds refers to the probability of LB reaching the flag leaf divided by the probability of it not reaching the flag leaf. Therefore, the OR is computed as the odds in the treatment group (a given fungicide program in this case) divided by the odds in the control group (the untreated check in this case). Consequently, if a fungicide program is effective at protecting the flag leaf, the overall odds for that program will be smaller than the odds for the control, and the OR will be less than 1.

Fungicide program effects on grain yield. As part of the primary analysis, PROC GLIMMIX of SAS was used to determine the effects of cultivar, fungicide treatment, and inoculation on grain yield. Each environment was analyzed separately by fitting a linear mixed model with fixed effects of cultivar, fungicide program, and inoculation main effects, all two-way interactions, and the three-way interaction, as well as random effects for block, whole-plot error, subplot error, and sub-subplot error (for split-split plot experiments). The lsmeans statement in GLIMMIX was used to estimate the expected values (means) for main effects and relevant interactions. The estimated means for the interaction of fungicide program and cultivar were used in a multivariate random-effects meta-analysis across all studies in order to estimate the overall mean yield difference between each fungicide program and the control $(\bar{D})$, along with their $95 \%$ confidence interval and the between-study variance $\left(\hat{\sigma}^{2}\right)$. Fixed within-study weights were estimated from the residual variances, and the meta-analytical model was fitted to the data in PROC MIXED of SAS using maximum likelihood, as described in detail elsewhere (Madden and Paul 2011; Paul and Madden 2014).

Effect of baseline disease level on yield response to fungicide programs. The meta-analysis was expanded to determine whether baseline disease levels, as influenced by cultivar reaction, affected $\bar{D}$ for each fungicide program. Each study was assigned a code of 0 or 1 based on disease severity in the untreated check, with 0 representing lesions restricted below the flag leaf ( 0 to 7 on the original 0 -to-10 scale) and 1 representing lesions on the flag leaf (8 to 10 on the original 0 -to-10 scale). The multivariate meta-analytical model was then refitted with LB severity code as a categorical fixed-effect moderator variable (Madden and Paul 2011; Paul et al. 2010, 2011). In brief, the model was again fitted in PROC MIXED of SAS, and a $\chi^{2}$ test was used to determine whether the moderator variable had a significant effect on the mean effect sizes $(\bar{D})$. Linear contrasts (through the estimate statement in PROC MIXED) were then used to estimate mean effect sizes, their standard errors, and 95\% CI for each level of the moderator variable for each fungicide program, as previously described (Madden and Paul 2011; Paul et al. 2010, 2011).

Projected yield response to different fungicide programs. Because marginal yield increases due to a fungicide treatment may not always be sufficient to offset costs associated with fungicide application, farmers are often interested in the chance or likelihood of a given fungicide program being profitable, as well as the expected magnitude of the profit. This is essentially a question about yield response in relation to fungicide application cost, grain price, and the distribution of the fungicide effects on yield. As demonstrated previously (Paul et al. 2008b, 2010, 2011), the estimated expected effect size ( $\bar{D}$ in this case) for each fungicide program and $\hat{\sigma}_{D}^{2}$ (estimated between-study variance for the difference, based on the between-study variances and covariances for the means) from the meta-analysis can be used to estimate the probability of yield responses in new randomly selected studies - done in a manner similar to those described in this studybeing above some critical level. We label the critical level $D_{C}$ (for instance, a yield increase greater than some minimum level needed to offset disease management cost). As a way of assessing the costbenefit of the fungicide programs evaluated in this study, probabilities were estimated for each program for a range of $D_{C}$ as $\rho=\varnothing\left(\left(\bar{D}-D_{C}\right) / \hat{\sigma}_{D}\right)$ (Paul et al. 2008b, 2010, 2011), where $\varnothing(\bullet)$ is the cumulative standard-normal function and $\hat{\sigma}_{D}$ is the estimated between-study standard deviation for the difference.

\section{Results}

Fungicide program and cultivar effect on LB severity. Although plots were inoculated at early crop development stages (at Feekes 6 and 9), disease onset was generally late in all environments. In most cases, lesions only reached the upper two leaves after full head emergence (Feekes 10.5). LB severity at the Feekes 10.5.4/11.1 growth stage varied among environments (Fig. 1). However, there were plants in each fungicide program with lesions on each of the four leaves, as indicated by severity scores on the ordinal scale ranging from 0 to 10 (Table 1; Fig. 1). IL11 and IL12 had the highest levels of disease, with mean severity on the flag leaf, averaged across fungicide programs and cultivars, being greater than $25 \%$ in both cases. This corresponded to a severity score of 10 on the ordinal scale. Conversely, WI11 had the lowest level of disease, with $50 \%$ of the samples having severity scores between 0 and 3 . Lesions were mostly restricted to the second and third leaves below the flag leaf (leaves 3 and 4), with severity between 1 and 5\%. For four (IL10, IN10, WI10, and IL12) of the other five environments, lesions reached the leaf immediately below the flag leaf (leaf 2 ) fairly consistently, with severity ranging from 1 to $>15 \%$. In OH10, severity was $>15 \%$ on leaf 3 and between 1 and $5 \%$ on leaf 2 . OH10 had the widest range of severity, with $50 \%$ of the samples having severity scores between 1 ( 1 to $50 \%$ severity on leaf 4$)$ and 8 ( 1 to $5 \%$ on the flag leaf), whereas IN12 had the narrowest range, with $50 \%$ of the scores between 6 and 8 (Fig. 1; Table 1).

With few exceptions (IL11 and IN12), the main and interaction effects of inoculation treatment on LB at Feekes 10.5.4/11.1 were not statistically significant $(P>0.05$; Table 2$)$, suggesting that both artificially inoculated and noninoculated plots had comparable levels of disease (averaged across cultivars and fungicide treatments) in most environments. This further suggests that much of the disease development was due to background inoculum from $P$. nodorum and other LB pathogens. Similarly, the interaction effects of cultivar and fungicide program were not always statistically significant and, although the main effect of cultivar was significant in all cases (Table 2), the specific cultivar reaction in terms of LB severity was very inconsistent across environments. The cultivar classified as moderately resistant did not always have lower mean LB severity than the cultivar classified as moderately susceptible to LB. For all environments in which there was a significant cultivar-fungicide program interaction, the interaction effect was manifested largely through the magnitude of the difference in severity among treatments. 
A
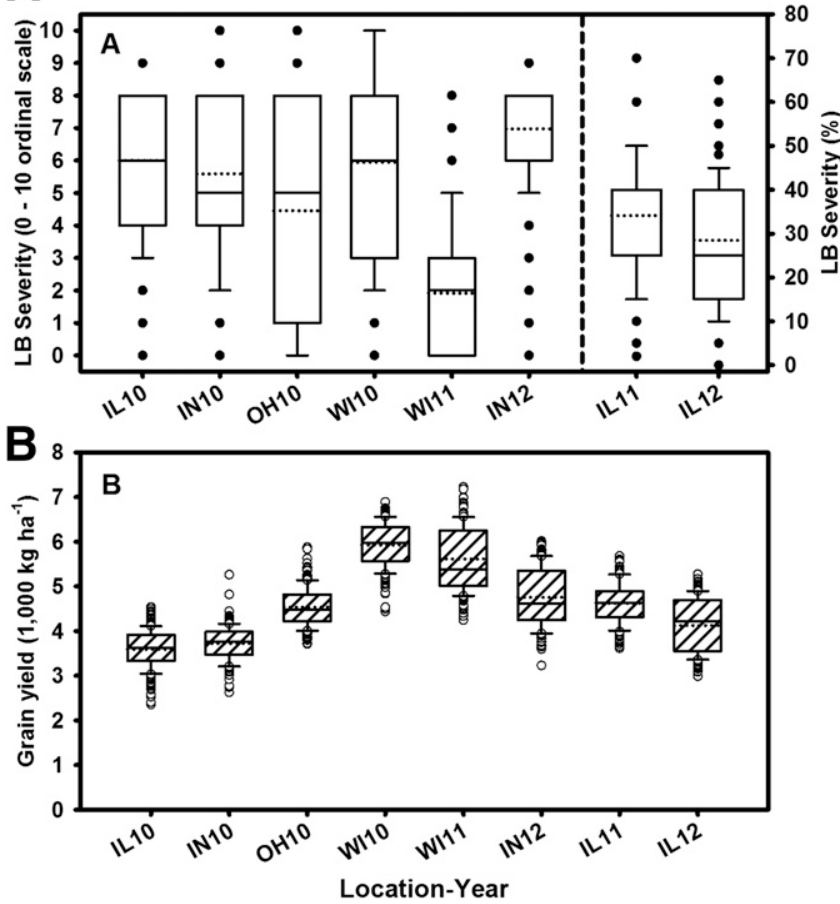

Fig. 1. Box plots showing the distribution of $A$, leaf blotch (LB) severity and $B$, grain yield in soft red winter wheat for field experiments conducted from 2010 to 2012 at the University of Illinois Crop Sciences Research and Education Center near Urbana (IL10, IL11, and IL12); Southwest Purdue Agricultural Center, Vincennes, IN (IN10 and IN12); Ohio Agricultural Research and Development Center Snyder Farm near Wooster (OH10); and University of Wisconsin Arlington Research Station, Arlington (W/10 and WI11). Within each box, the dotted line represents the mean and the solid line the median, whereas the top and bottom lines represent the 75th and 25th percentiles of the data, respectively. Vertical bars extending beyond the boxes represent the 10th and 90th percentiles and circles indicate outliers. For IL10, $n=216$; whereas, for the other experiments, $n=162$.
For instance, the magnitude of disease reduction with a given fungicide treatment relative to the untreated check was greater for DynoGro 9911 or 9922 than Pioneer 25R39 (data not shown).

Regardless of the cultivar, the fungicide program effect was statistically significant in all environments in which disease was prevalent on the upper two leaves (Table 2), and fairly consistent in terms of the treatments with the highest and lowest mean severity (Fig. 2). For all environments in which LB consistently reached the upper two leaves, treatments applied only at Feekes 5 had mean severity comparable with the untreated check. For both Headline and Prosaro, the Feekes-5-only treatments, PFULL5 and HFULL5, had severity scores between 5 and 7 (Fig. 2A to D), which corresponded to between 1 and $>15 \%$ severity on the leaf immediately below the flag leaf (leaf 2). Fungicide programs with an application at Feekes 8 or 10, including those that received split half-rate applications at Feekes 5 and Feekes 8 , had mean severity scores between 4 ( $>5 \%$ severity on leaf 3 ) and 5 (1 to 5\% on leaf 2). Similarly, for IL11, the environment in which disease was rated only on the flag leaf, programs with an application at Feekes 8 (PFULL8 and HFULL8), Feekes 10 (PFULL10 and HFULL10), or Feekes 5 and 8 (PHLF5+8 and HHLF5+8) had lower mean severity than PFULL5 and HFULL5 and the untreated check (Fig. 2E). In general, split half-rate fungicide programs (PHLF5+8 and HHLF5+8) showed efficacy comparable with programs with a single full-rate application at Feekes 8 or Feekes 10 in all environments (Fig. 2).

Fungicide program effects on the risk of $L B$ reaching the flag leaf. For all fungicide programs, the $\bar{L}_{O R}$ was significantly different from zero, based on the standard normal test from the metaanalysis $(P<0.05)$, indicating that all fungicide programs affected the likelihood of LB reaching the flag leaf. The estimated $\bar{L}_{O R}$ values ranged from -1.37 to -0.39 . The lowest $\mathrm{OR}, \mathrm{OR}=\exp \left(\bar{L}_{O R}\right)$, were for Headline applied at full rate at Feekes $8(0.25)$, followed by Prosaro applied at split half rates at Feekes 5 and $8(0.30)$, Prosaro at full rate at Feekes 10 (0.31), Headline applied at split half rates at Feekes 5 and 8 (0.33), Headline at full rate at Feekes 10 (0.38), and Prosaro at full rate at Feekes 8 (0.45) (Fig. 3). Programs with an application at Feekes 5 only had the highest overall OR, 0.68 for Prosaro and 0.63 for Headline. By definition, programs with OR closer to 1 (PFULL5

Table 2. Probability values (level of significance) from linear mixed model analyses of the effects of wheat cultivar (CV), fungicide program (PROG), and Parastagonospora nodorum inoculation (INOC) on leaf blotch (LB) severity and grain yield in field experiments conducted in four Midwest states from 2010 to $2012^{2}$

\begin{tabular}{|c|c|c|c|c|c|c|c|c|}
\hline \multirow[b]{2}{*}{ Factors $^{\mathbf{b}}$} & \multicolumn{4}{|c|}{2010} & \multicolumn{2}{|c|}{2011} & \multicolumn{2}{|c|}{2012} \\
\hline & IL10 & IN10 & OH10 & WI10 & IL11 & WI11 & IL12 & IN12 \\
\hline \multicolumn{9}{|l|}{ LB severity } \\
\hline $\mathrm{CV}$ & $<0.001$ & 0.002 & $<0.001$ & 0.030 & 0.005 & $<0.001$ & $<0.001$ & $<0.001$ \\
\hline PROG & $<0.001$ & $<0.001$ & $<0.001$ & $<0.001$ & $<0.001$ & 0.664 & $<0.001$ & $<0.001$ \\
\hline $\mathrm{CV} \times \mathrm{PROG}$ & 0.001 & 0.369 & 0.850 & 0.001 & 0.383 & 0.128 & 0.959 & 0.001 \\
\hline INOC & 0.461 & 0.117 & 0.655 & 0.669 & $<0.001$ & 0.711 & $\ldots$ & 0.617 \\
\hline $\mathrm{CV} \times \mathrm{INOC}$ & 0.101 & 0.432 & 0.612 & 0.920 & 0.136 & 0.589 & $\ldots$ & 0.721 \\
\hline PROG $\times$ INOC & 0.952 & 0.755 & 0.997 & 0.448 & 0.310 & 0.488 & $\ldots$ & $<0.001$ \\
\hline $\mathrm{CV} \times \mathrm{PROG} \times \mathrm{INOC}$ & 0.877 & 0.332 & 0.934 & 0.790 & 0.541 & 0.321 & $\ldots$ & 0.236 \\
\hline \multicolumn{9}{|l|}{ Grain yield } \\
\hline $\mathrm{CV}$ & 0.003 & 0.076 & 0.482 & 0.320 & 0.055 & $<0.001$ & 0.001 & 0.922 \\
\hline PROG & $<0.001$ & 0.276 & 0.031 & 0.069 & 0.309 & 0.133 & $<0.001$ & 0.337 \\
\hline $\mathrm{CV} \times \mathrm{PROG}$ & 0.191 & 0.561 & 0.440 & 0.660 & 0.754 & 0.666 & 0.639 & 0.131 \\
\hline INOC & 0.952 & 0.791 & 0.807 & 0.648 & 0.829 & 0.498 & 0.900 & 0.262 \\
\hline $\mathrm{CV} \times \mathrm{INOC}$ & 0.570 & 0.793 & 0.255 & 0.270 & 0.762 & 0.530 & 0.491 & 0.919 \\
\hline PROG $\times$ INOC & 0.789 & 0.867 & 0.305 & 0.497 & 0.457 & 0.059 & 0.948 & 0.674 \\
\hline $\mathrm{CV} \times \mathrm{PROG} \times \mathrm{INOC}$ & 0.069 & 0.592 & 0.355 & 0.516 & 0.830 & 0.205 & 0.831 & 0.554 \\
\hline
\end{tabular}

a Field experiments were conducted from 2010 to 2012 at the University of Illinois Crop Sciences Research and Education Center near Urbana (IL10, IL11, and IL12); Southwest Purdue Agricultural Center, Vincennes, IN (IN10 and IN12); Ohio Agricultural Research and Development Center Snyder Farm near Wooster (OH10); and University of Wisconsin Arlington Research Station, Arlington (WI10 and WI11).

${ }^{\mathrm{b}} \mathrm{CV}=$ Soft red winter wheat Pioneer 25R39 (moderately susceptible to Stagonospora leaf blotch [SLB]) and Dyna Gro 9911 (Illinois, Indiana, and Wisconsin) or Dyna Gro 9922 (Ohio) (both moderately resistant to SLB); PROG = a single full rate of the fungicides Prosaro 421 SC $(19 \%$ tebuconazole $+19 \%$ prothioconazole) or Headline (23.6\% pyraclostrobin) applied at Feekes growth stage 5, 8, or 10 or split half rates applied at Feekes 5 and 8; and INOC $=$ spray inoculation with a spore suspension of $P$. nodorum at Feekes growth stages 6 or 9 or noninoculated. Inoculum was applied at $5 \times 10^{5}$ spores $/ \mathrm{ml}$ in 2010 and $10 \times 10^{5}$ spores/ml in 2011 and 2012. 
and HFULL5) were the least effective at protecting the flag leaf, whereas those with the smallest OR (HFULL8, PFULL10, and PHLF5+8) were the most effective (Fig. 3).

The OR can also be used to quantify the relative risk of LB reaching the flag leaf. For instance, an OR of 0.25 can be interpreted to mean that, relative to the untreated check, the application of Headline at Feekes 8 (HFULL8) reduced the odds of LB reaching the flag leaf by $75 \%$. Similarly, Prosaro at half rate at Feekes 5 and 8 (PHLF5+8) and at full rate at Feekes 10 (PFULL10) reduced the odds by approximately $70 \%$ but the two Feekes 5-only programs reduced the odds by about 32 and $37 \%$. All programs showed a fairly wide range of efficacy across trials in term of protection of the flag leaf. The width of the $95 \%$ CI around OR was very wide for all fungicide programs, likely reflecting the small number of environments used in this investigation (Fig. 3). However, in no case did the $\mathrm{CI}$ include 1 , confirming the statistical significance of the treatment effects relative to the check. HFULL8, HFULL10, and PHLF5+8 had the narrowest CI: 0.13 to $0.51,0.22$ to 0.66 , and 0.14 to 0.61 , respectively. These corresponded to odds reductions of 49 to $87 \%$ for HFULL8, 44 to $78 \%$ for HFULL10, and 39 to $86 \%$ for PHLF5+8.

Fungicide program and cultivar effects of yield. Minimum, mean, and maximum grain yield across all eight environments were 2.4, 4.6, and 7.2 $\mathrm{MT} \mathrm{ha}^{-1}$ (37.6, 73.2, and 115.1 bushel/acre), respectively. Averaged across cultivars and fungicide programs, mean yields were highest in WI10 (5.9 MT ha ${ }^{-1}$ ) and WI11 (5.6 MT ha-1) and lowest in IL10 (3.6 MT ha ${ }^{-1}$ ) and IN10 (3.7 $\mathrm{MT} \mathrm{ha}^{-1}$ ) (Fig. 1). The effects of two- and three-way interactions of fungicide program, cultivar, and inoculation treatment on yield were not statistically significant in any of the eight environments (Table 1). In seven of the eight environments, Pioneer 25R39 (classified as moderately susceptible to SLB) had mean yields comparable with or significantly higher yields than DynoGro 9911 or 9922 (classified as moderately resistant to SLB). The statistical significance of fungicide program effects on yield varied among environments (Table 2). The untreated check and programs with a Feekes 5-only application were consistently among those with the lowest mean yield. Averaged across environments and cultivars, mean yield in the check was $4,462 \mathrm{~kg} \mathrm{ha}^{-1}$, compared with 4,580 and $4,594 \mathrm{~kg} \mathrm{ha}^{-1}$ for the Feekes 5-only programs, 4,652 and $4,659 \mathrm{~kg} \mathrm{ha}^{-1}$ for the Feekes 8 programs, 4,682 and 4,707 $\mathrm{kg} \mathrm{ha}^{-1}$ for the Feekes 10 programs, and 4,689 and 4,739 for the Feekes $5+8$ split half-rate application programs.

As indicated by the results from the meta-analysis in Table 3, the overall mean effect size $(\bar{D})$ was significantly different from zero $(P \leq 0.003$, based on the standard normal test) for fungicide programs with a full-rate application at Feekes 8 (PFULL8 and HFULL8) or Feekes 10 (PFULL10 and HFULL10), or split halfrate applications at Feekes 5 and 8 (PHLF5+8 and HHLF5+8). $\bar{D}$ was highest for PFULL10 $\left(245 \mathrm{~kg} \mathrm{ha}^{-1}\right)$, followed by HFULL10
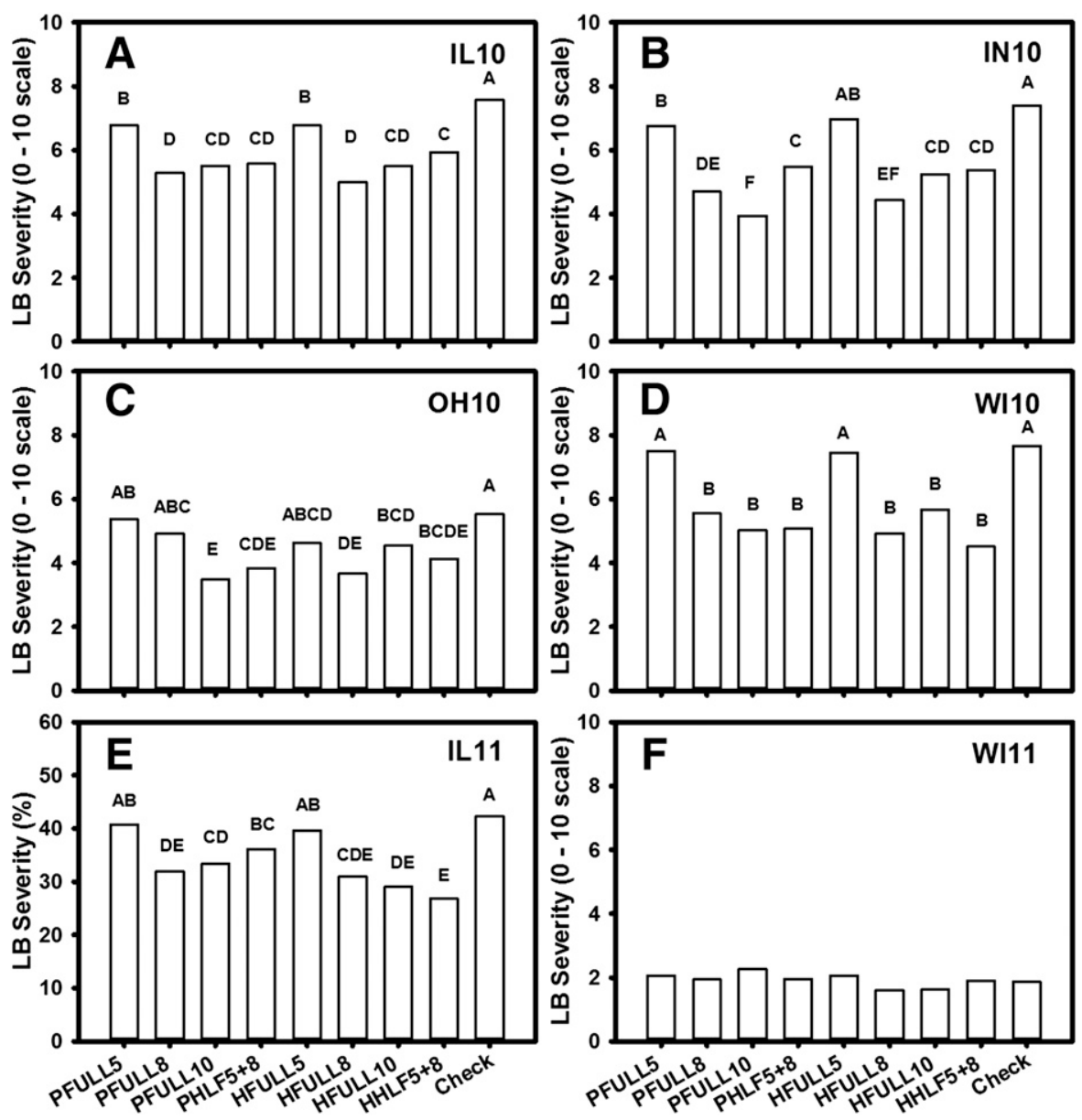

Fig. 2. Mean leaf blotch (LB) severity for different fungicide programs from field experiments conducted in 2010 and 2011 at the University of Illinois Crop Sciences Research and Education Center near Urbana (A and E); Southwest Purdue Agricultural Center, Vincennes, IN (B); Ohio Agricultural Research and Development Center Snyder Farm near Wooster (C); and University of Wisconsin Arlington Research Station, Arlington (D and F). Fungicide programs were Prosaro 421 SC $(19 \%$ tebuconazole $+19 \%$ prothioconazole) applied at full rate $\left(475 \mathrm{ml} \mathrm{ha}^{-1}\right)$ at Feekes growth stage 5 (PFULL5), 8 (PFULL8), or 10 (PFULL10) or split half rates applied at Feekes 5 and 8 (PHLF5+ 8); Headline (23.6\% pyraclostrobin) applied at full ( $438 \mathrm{ml} \mathrm{ha}^{-1}$ ) at Feekes 5 (HFULL5), 8 (HFULL8), or 10 (HFULL10) or split half rates applied at Feekes 5 and 8 (HHLF5+ 8); and untreated check (Check). Bars represent averages across 18 to 24 experimental units (i.e., across the levels of the other treatment factors in the study). Means with the same letter are not statistically different from each other at $P \leq 0.05$. Statistical analyses and comparisons were based on mean ranks; however, for presentation, the original raw data means are shown. Note: data for IL12 and IN12 are not shown here because four of the eight treatments were not applied. 
(233 kg ha $\left.{ }^{-1}\right), \operatorname{HHLF} 5+8\left(220 \mathrm{~kg} \mathrm{ha}^{-1}\right)$, HFULL8 $\left(187 \mathrm{~kg} \mathrm{ha}^{-1}\right)$, and PFULL8 and PHLF5+8 $\left(175 \mathrm{~kg} \mathrm{ha}^{-1}\right)$ (Table 3$)$. Estimated $\bar{D}$ for the Feekes 5-only application programs, $61 \mathrm{~kg} \mathrm{ha}^{-1}$ for Prosaro and $79 \mathrm{~kg} \mathrm{ha}^{-1}$ for Headline, were not significantly different from zero $(P>0.20)$. In addition, differences in mean yield between Prosaroand Headline-based programs were not statistically significant $(P>$ 0.40; Table 3).

Projected yield response and baseline disease effect of $\bar{D}$. All of the fungicide programs with a full-rate application at Feekes 8 (PFULL8 and HFULL8) or Feekes 10 (PFULL10 and HFULL10) or half-rate applications at Feekes 5 and 8 (PHLF5+8 and HHLF5+8) had more than a $80 \%$ chance of resulting in a positive yield

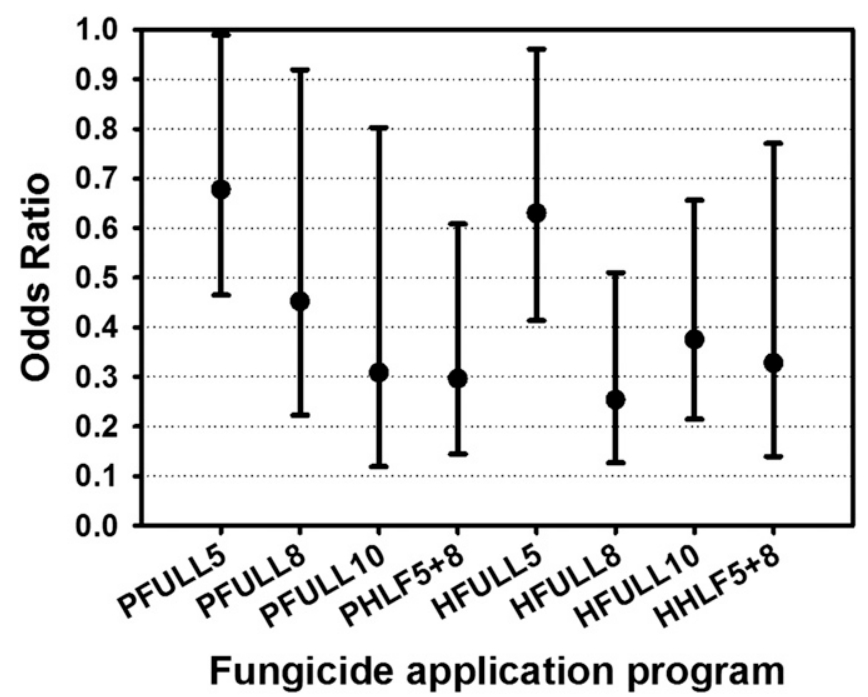

Fig. 3. Overall odds ratios for the effects of different fungicide programs on leaf blotch (LB) severity at Feekes growth stage 10.5.4/11.1 (i.e., the odds of LB reaching the flag leaf for each program relative to the odds in the untreated check). Dots represent backtransformed mean log odds ratios estimated through random-effects meta-analyses of data from field experiments conducted in four Midwest states in 2010 and 2011. Error bars are the $95 \%$ confidence intervals around the odds ratios. Fungicide programs were Prosaro 421 SC (19\% tebuconazole $+19 \%$ prothioconazole) applied at full rate $\left(475 \mathrm{ml} \mathrm{ha}^{-1}\right)$ at Feekes growth stage 5 (PFULL5), 8 (PFULL8), or 10 (PFULL10) or split half rates applied at Feekes 5 and 8 (PHLF5+8), or Headline (23.6\% pyraclostrobin) applied at full (438 $\mathrm{ml} \mathrm{ha}^{-1}$ ) at Feekes 5 (HFULL5), 8 (HFULL8), or 10 (HFULL10) or split half rates applied at Feekes 5 and 8 (HHLF5+8). response in a new random study (Fig. 4A) conducted in a manner and under conditions similar to those described here. Of these, PFULL10, HFULL10, and HHLF5+8, in that order, had the highest probabilities of resulting in yield responses between 1 and 600 $\mathrm{kg} \mathrm{ha}^{-1}$. The Feekes 5-only fungicide programs (PFULL5 and HFULL5) had about a 63 to $67 \%$ chance of resulting in a positive yield response, and the lowest probabilities of yield responses between 1 and $600 \mathrm{~kg} \mathrm{ha}^{-1}$. In all cases, the probabilities decreased as the projected yield response increased.

For all programs, the probability of obtaining a yield response high enough to offset fungicide application cost (break even) decreased as application cost increased and increased as grain price increased (Figs. 4B to D and 5). For instance, if fungicide application cost (product + application) is $\$ 36 \mathrm{ha}^{-1}$ and grain price is $\$ 0.18 \mathrm{~kg}^{-1}$, then, based on the $\bar{D}$ values and between-study variance $\left(\hat{\sigma}^{2}\right)$ from the metaanalysis, the probability of profitability (i.e., obtaining a yield response high enough to offset the application cost; $\$ 36 \mathrm{ha}^{-1} / \$ 0.18 \mathrm{~kg}^{-1}=200$ $\left.\mathrm{kg} \mathrm{ha}^{-1}\right)$ was estimated at approximately $0.45([175.36-200] / \sqrt{32,412})$ for PFULL8 and PHLF5+8, 0.47 for HFULL8, 0.54 for HHLF5+8, 0.57 for HFULL10, and 0.60 for PFULL10 (Fig. 4A and C). The corresponding probabilities were 0.22 and 0.25 for PFULL5 and HFULL5, respectively. However, at that same grain price, the probabilities of obtaining a $300 \mathrm{~kg} \mathrm{ha}^{-1}$ (4.5 bushel/acre) yield increase necessary to break even at a higher application cost of $\$ 55.25 \mathrm{ha}^{-1}$ were lower, ranging from 0.24 to 0.37 for Feekes 8, Feekes 10, and Feekes 5+8 programs, and from 0.9 to 0.11 for Feekes 5-only programs (Fig. 4A and C).

Based on $\chi^{2}$ tests from the meta-analysis, the effect of baseline disease as a categorical moderator variable on $\bar{D}$ (the yield response) was only statistically significant $(P<0.10)$ for three (PFULL5, PFULL8, and HHLF5+8) of the eight fungicide programs evaluated. However, for all programs, $\bar{D}$ was numerically higher when disease reached the flag leaf (category 1 of the moderator variable) compared with when disease was restricted to leaves below the flag leaf (category 0 of the moderator variable). For category 0 , the $\bar{D}$ values were $-201,-50$, and $39 \mathrm{~kg} \mathrm{ha}^{-1}$ for PFULL5, PFULL8, and HHLF5+8, respectively, compared with 150,243 , and $281 \mathrm{~kg} \mathrm{ha}^{-1}$ for category 1 . The width of $95 \% \mathrm{CI}$ around $\bar{D}$ was very wide for all fungicide programs and, in all cases, included zero for category 0 of the moderator variable (data not shown).

The break-even probabilities were higher when LB reached the flag leaf than when restricted to leaves below the flag leaf (Fig. 5). For all grain prices and application costs evaluated, the probability of break even was less than $30 \%$ when LB was restricted to leaves below the flag leaf. However, when LB reached the flag leaf at

Table 3. Mean difference (effect size) and corresponding statistics from multivariate random-effects meta-analysis of the effect of fungicide programs for management of leaf blotch diseases on grain yield in soft red winter wheat from field experiments conducted in Illinois, Indiana, Ohio, and Wisconsin between 2010 and $2012^{\mathrm{a}}$

\begin{tabular}{|c|c|c|c|c|c|c|}
\hline Contrast $^{\mathbf{b}}$ & $\bar{D}$ & $\operatorname{se}(\bar{D})$ & $\mathbf{Z}$ & $P$ & $C I_{L}$ & $C \boldsymbol{I}_{U}$ \\
\hline CK versus PFULL5 & 61.02 & 63.10 & 0.97 & 0.334 & -62.81 & 184.84 \\
\hline CK versus PFULL8 & 175.36 & 59.38 & 2.95 & 0.003 & 58.84 & 291.88 \\
\hline CK versus PFULL10 & 244.60 & 59.38 & 4.12 & $<0.001$ & 128.08 & 361.12 \\
\hline CK versus PHLF5+8 & 174.83 & 63.10 & 2.77 & 0.006 & 51.01 & 298.66 \\
\hline CK versus HFULL5 & 79.14 & 63.10 & 1.25 & 0.210 & -44.68 & 202.97 \\
\hline CK versus HFULL8 & 187.13 & 59.38 & 3.15 & 0.002 & 70.61 & 303.65 \\
\hline CK versus HFULL10 & 232.85 & 59.38 & 3.92 & $<0.001$ & 116.33 & 349.37 \\
\hline CK versus HHLF5+8 & 220.45 & 63.10 & 3.49 & 0.001 & 96.62 & 344.27 \\
\hline PFULL5 versus HFULL5 & 18.13 & 65.47 & 0.28 & 0.782 & -110.35 & 146.61 \\
\hline PFULL8 versus HFULL8 & 11.77 & 59.38 & 0.20 & 0.843 & -104.75 & 128.29 \\
\hline PFULL10 versus HFULL10 & -11.75 & 59.38 & -0.20 & 0.843 & -128.27 & 104.77 \\
\hline PFULL5+8 versus HFULL5+8 & 45.61 & 65.47 & 0.70 & 0.486 & -82.87 & 174.09 \\
\hline
\end{tabular}

a $\bar{D}=$ effect size as mean grain yield difference for each fungicide treatment relative to the untreated check; se $(\bar{D})=\operatorname{standard}$ error of $\bar{D} ;$ lower $\left(C I_{L}\right)$ and upper $\left(C I_{U}\right)$ limits of the $95 \%$ confidence interval around $\bar{D}$; and $Z$ (standard normal) statistic from the meta-analysis. $P=$ probability value (significance level) for the effect of treatment on yield.

b Prosaro $421 \mathrm{SC}\left(19 \%\right.$ tebuconazole $+19 \%$ prothioconazole) applied at full rate $\left(475 \mathrm{ml} \mathrm{ha}^{-1}\right)$ at Feekes growth stage 5 (PFULL5), 8 (PFULL8), or 10 (PFULL10) or split half rates applied at Feekes 5 and 8 (PHLF5+8); Headline (23.6\% pyraclostrobin) applied at full rate (438 $\mathrm{ml} \mathrm{ha}^{-1}$ ) at Feekes 5 (HFULL5), 8 (HFULL8), or 10 (HFULL10) or split half rates applied at Feekes 5 and 8 (HHLF5+8); and untreated check (CK). 
application costs below $\$ 60 \mathrm{ha}^{-1}$ and a grain price $\$ 26 \mathrm{~kg}^{-1}$, the break-even probabilities ranged from 30 to $52 \%$ for the PFULL5 program (Prosaro at full rate at Feekes 5), 52 to $73 \%$ for the PFULL8 program (Prosaro at full rate at Feekes 8 ), and 61 to $80 \%$ for the HHLF5+8 program (Headline at half rate at Feekes 5 and 8) (Fig. 5C). At grain prices below $\$ 26 \mathrm{~kg}^{-1}$ (Fig. 5A and B) and application cost above $\$ 60 \mathrm{ha}^{-1}$, the probabilities were substantially lower, even when LB reached the flag leaf.

\section{Discussion}

Most of the existing foliar disease management guidelines in SRWW in the Great Lakes region were developed using older fungicides on older cultivars, and at a time when grain prices were consistently low. As grain prices have increased, and fungicides with effects on crop physiology and cultivars with higher yield potential have become available, several new fungicide application programs have emerged. These include applications before Feekes 8 (the socalled "green-up" or early applications), applications at half rate at green-up (Feekes 4 to 6) followed by a second half rate at Feekes 8 or 10 (also known as split applications), and applications when the risk of disease or actual disease levels are low (commonly referred to "plant-health" applications). However, most of these programs are being implemented without adequate data pertaining to their efficacy in terms of disease reduction and yield increase.

Here, we present results from a coordinated study conducted over 3 years to comparatively and simultaneously evaluate fungicide programs, using two of the most widely recommended foliar fungicides, Prosaro 421 SC (19\% tebuconazole $+19 \%$ prothioconazole) and Headline (23.6\% pyraclostrobin), on SRWW in the Great Lakes region. Instead of relying on a count of the number of environments with a statistically significant fungicide program effect to draw conclusions about yield and disease responses (vote counting), meta-analysis was used to determine the overall magnitude and significance of fungicide program effects across environments. The fallacy of vote counting and the advantages of meta-analysis, particularly its high statistical power, were discussed in detail elsewhere (Madden and Paul 2011). Based on results from meta-analyses of $L_{O R}$, the greatest protection of the flag leaf occurred when Headline or Prosaro were applied at full rate at either Feekes 8 or Feekes 10. Interestingly, split half-rate applications of the two fungicides at Feekes 5 and Feekes 8 provided disease control comparable with single full-rate applications at Feekes 8 or 10. These programs also resulted in the highest mean yield response relative to the check (based on $\bar{D}$ from the meta-analysis). Feekes 5-alone applications were the least effective in terms of disease control, and resulted in the lowest mean yield responses. Also based on results from the meta-analyses, differences in mean yield between Headline and Prosaro were not statistically significant.

We hypothesize that applications at Feekes 5 alone were likely too early to adequately protect the upper leaves. Although plots were inoculated at Feekes 6 or 9, disease onset generally did not occur until Feekes 8 to 10, and lesions did not reach the flag leaf until after head emergence (Feekes 10.5). This was consistent with observations made by Shaner and Buechley (1995) based on data collected in Indiana over a 19-year period and by Milus and Chalkley (1997) in plots planted with $P$. nodorum-infected seed. The lack of significant inoculation treatment effect and relatively late disease onset could be attributed, in part, to the fact that optimum conditions for infection and LB development (Bergstrom 2010; McMullen 2010; Shaner 2010) typically occurs in mid- to late May in the Great Lakes region. Therefore, when applied at Feekes 5 only, the residual effect of Headline or Prosaro was likely not sufficient to provide protection against infections at and after Feekes 8. For management of foliar diseases of wheat, these fungicides are generally used as protectants, meaning that they need to be applied directly to the plant part being protected before infection occurs in order to be fully effective (Mueller and Bradley 2008). At the time of the Feekes 5 applications, the
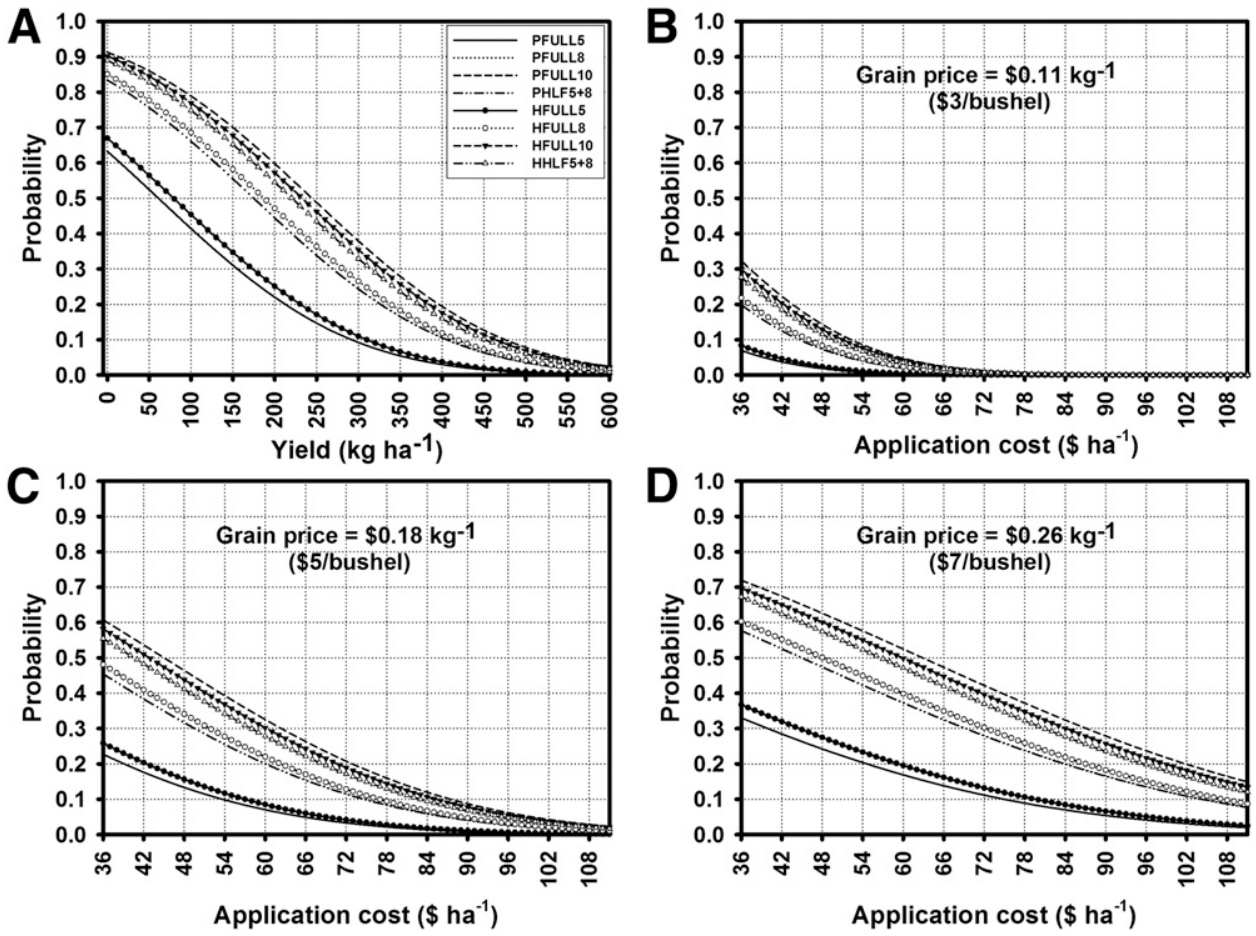

Fig. 4. Estimated probability of different fungicide programs in a randomly selected new study resulting in A, yield increases of 1 to $600 \mathrm{~kg} \mathrm{ha}^{-1}$ relative to the untreated check; and $\mathbf{B}, \mathbf{C}$, and $\mathbf{D}$, profitability of break even at grain prices of $\$ 0.11, \$ 0.18$, and $\$ 0.26 \mathrm{ha}^{-1}$, respectively, for a range of applications costs. Estimates were based on mean effect sizes and between-study variances from a multivariate random-effects meta-analysis of data from field experiments conducted in four Midwest states from 2010 to 2012 to evaluate the effects of fungicide treatments (for leaf blotch control) on grain yield. Fungicide programs were Prosaro $421 \mathrm{SC}$ (19\% tebuconazole $+19 \%$ prothioconazole) applied at full rate $\left(475 \mathrm{ml} \mathrm{ha}^{-1}\right.$ ) at Feekes growth stage 5 (PFULL5), 8 (PFULL8), or 10 (PFULL10) or split half rates applied at Feekes 5 and 8 (PHLF5+8); or Headline (23.6\% pyraclostrobin) applied at full (438 ml ha ${ }^{-1}$ ) at Feekes 5 (HFULL5), 8 (HFULL8), or 10 (HFULL10) or split half rates applied at Feekes 5 and 8 (HHLF5+8). Lines without symbols are for Prosaro, whereas those with symbols are for Headline. Feekes 5 applications are represented by solid lines, Feekes 8 applications by dotted lines, Feekes 10 applications by broken lines, and Feekes $5+8$ applications by broken lines with dots. 
uppermost leaves had not yet emerged and, as such, likely received little or no fungicide coverage, given that systemic movement of both is very limited (Mueller and Bradley 2008). Consequently, infections likely occurred, leading to comparable disease levels in the Feekes 5only fungicide programs and the untreated check. However, when the Feekes 5 applications were followed by a second application at
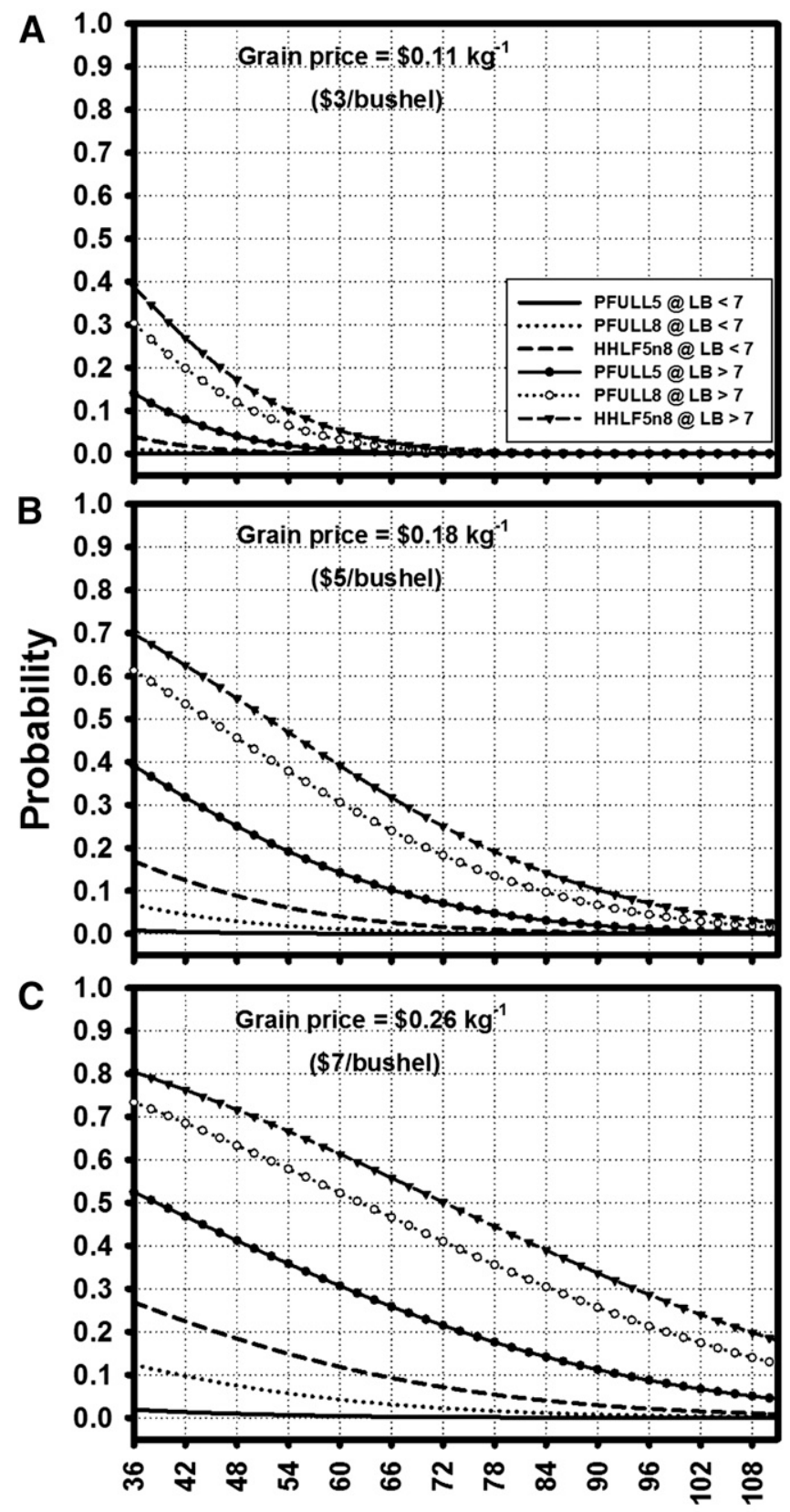

\section{Application cost $\left(\$ \mathrm{ha}^{-1}\right)$}

Fig. 5. Estimated probability of break even for three fungicide programs at high and low baseline levels of leaf blotch (LB) severity ( $>7$ and $\leq 7$, respectively) at grain prices of $\mathbf{A}, \$ 0.11 ; \mathbf{B}, \$ 0.18$; and $\mathbf{C}, \$ 0.26 \mathrm{ha}^{-1}$ for a range of applications costs. Estimates were based on mean effect sizes and the between-study variance from a multivariate random-effects meta-analysis of the effects of baseline LB severity on yield response to fungicide programs for data from field experiments conducted in four Midwest states from 2010 to 2012. PFULL5 (solid lines) and PFULL8 (dotted lines) represent Prosaro 421 SC (19\% tebuconazole $+19 \%$ prothioconazole) applied at full rate $\left(475 \mathrm{ml} \mathrm{ha}^{-1}\right)$ at Feekes growth stage 5 and 8 , respectively; and HHLF5+8 (broken lines) represents Headline $(23.6 \%$ pyraclostrobin) applied at split half rates at Feekes 5 and 8 . Lines without symbols are for low baseline levels of LB ( $\leq 7$ represents studies in which LB lesions were restricted to leaves below the flag leaf), whereas those with symbols are for high baseline LB severity (>7 represents studies in which LB lesions reached the flag leaf).
Feekes 8, even at half the recommended rate, disease control was superior to that of the full-rate application at Feekes 5 only and comparable with that of the Feekes 8 and Feekes 10 applications. This suggests that, in the split-application programs, it was the Feekes 8 and not the Feekes 5 application that provided protection against infection.

The benefit of fungicide applications between Feekes 8 and 10.5 for foliar disease management and wheat grain yield and quality increase has been well documented. However, there have been conflicting reports on the efficacy of pre-flag-leaf-emergence fungicide applications. Although findings similar to those observed here in terms of the inferior efficacy of green-up-only applications have been previously reported (Hershman et al. 2011; Waxman and Bergstrom 2010; Wiersma et al. 2012), in some studies in which there was early disease development, green-up-only applications (Feekes 4 to 6) provided higher or similar levels of foliar disease reduction to Feekes 8 or Feekes 10 applications (Marroni et al. 2006; Rideout and Waldenmaier 2012) and resulted in significant yield increases relative to the untreated check (Rideout and Waldenmaier 2012). This was particularly true in studies with fairly high levels of early-season, lower canopy diseases such as powdery mildew (Rideout and Waldenmaier 2012) and Septoria tritici blotch (Marroni et al. 2006). For instance, Rideout and Waldenmaier (2012) reported that all fungicide treatments applied at tillering, including Headline at half the label recommended rate $\left(219 \mathrm{ml} \mathrm{ha}^{-1}\right)$, had significantly lower powdery mildew severity on the flag leaf and the leaf below the flag leaf and significantly higher grain yield than the untreated check. Mean powdery mildew severity in the untreated check was greater than $28.8 \%$ on leaf 2 and $8.8 \%$ on the flag leaf. These results suggest that Feekes 5 applications may be of value for managing early-season foliar disease when conditions are conducive for their development. Powdery mildew levels were generally low in all environments of our study because the cultivars used were not highly susceptible to this disease (Beuerlein et al. 2010). We were unable to enhance early disease development with our inoculations, likely because SLB can remain asymptomatic on lower leaves at temperatures between 9 and $25^{\circ} \mathrm{C}$ (Shah and Bergstrom, 2000), or simply because early-season conditions were not favorable for SLB development or for natural infection and development of other leaf blotching diseases.

Our results further showed that, under the conditions of this investigation, cultivar had a significant effect on LB in all environments but the specific disease reaction of the cultivars varied considerably from one environment to another. In four of the eight environments, DynoGro 9911 or 9922 , classified as moderately resistant to SLB, had higher mean LB severity than Pioneer 25R39, classified as moderately susceptible to SLB. Several factors may have contributed to such a variation, including the fact that SLB was not the only disease rated. LB represented total leaf blotching disease severity, which included SLB as well as Septoria tritici blotch and likely tan spot, common members of the wheat foliar disease complex in the Great Lakes region (Engle et al. 2006; Shaner and Buechley 1995) that are not always easy to distinguish from SLB solely on the basis of visual symptoms (Bergstrom 2010; McMullen 2010; Shaner 2010). Cultivars with SLB resistance may not be resistant to Septoria tritici blotch or tan spot (Gurung et al. 2012; Singh et al. 2006). Because the range of optimum conditions for infection and development of the three diseases overlap considerably (Bergstrom 2010; McMullen 2010; Shaner 2010), Septoria tritici blotch (and possibly tan spot) likely reached levels of severity higher than or comparable with SLB in some environments, resulting in the moderately SLB-resistant (but potentially Septoria blotch- or tan spot-susceptible) cultivar having total LB severity (the sum of the three diseases) comparable with or higher than that of the moderately SLB-susceptible cultivar. Unfortunately, tan spot and Septoria tritici blotch resistance classifications were not available for the three cultivars used in this study; only SLB was rated in the disease-screening nurseries and the performance trials from which the cultivars were selected (Beuerlein et al. 2010).

To account for the fact that the disease reaction of the cultivars used in this study was not necessarily related to their resistance 
classification for the diseases actually present, LB severity class was used as the fixed effect in the meta-analysis of the effect of fungicide program on grain yield. Each cultivar-environment combination was assigned to one of two severity classes based on LB in the untreated check $(0=$ low disease level corresponding to lesions restricted below the flag leaf and $1=$ high disease level corresponding to lesions on the flag leaf), and the model was fitted with LB severity class as a moderator variable (Madden and Paul 2011; Paul et al. 2008b). The effect of LB severity class on the yield response $(\bar{D})$ was only statistically significant for three of the eight fungicide programs (PFULL5, PFULL8, and HHLF5+8) evaluated, with the high LB severity class having significantly higher $\bar{D}$ than the low severity class. In both severity classes, the application of Prosaro at Feekes 8 or Headline at Feekes 5 and 8 resulted in higher $\bar{D}$ values than the Feekes 5 program. Similar trends were observed for the other programs. This suggested that the magnitude of the yield response to the Headline and Prosaro fungicide programs evaluated here had a tendency to be higher when LB reaches the flag leaf (relatively high baseline disease levels) than when restricted to leaves below the flag leaf (relatively low baseline disease levels). This is consistent with results from other studies on the effects of baseline disease levels on yield response to foliar fungicides in wheat (Lopez et al. 2015; Ransom and McMullen 2008; Thompson et al. 2014) and maize (Paul et al. 2011).

Understandably, the fungicide programs that resulted in the greatest reduction in disease intensity (those with an application at Feekes 8 or 10) resulted in the higher estimated yield responses to fungicide $(\bar{D})$ and, consequently, had the highest probabilities of being profitable in future studies. For instance, if total fungicide application cost (product + application) is $\$ 37.07 \mathrm{ha}^{-1}$ and grain price is $\$ 0.257 \mathrm{~kg}^{-1}$, the probability of profitability (i.e., obtaining a yield response high enough to offset the application cost) was estimated at 0.71 and 0.69 for PFULL10 and HFULL10, two of the most efficacious fungicide programs in terms of flag leaf protection, compared with 0.32 for PFULL5 and 0.36 for HFULL5, the least efficacious programs. Even if one makes adjustments for the fact that damage from wheel tracks made during Feekes 8 or 10 applications may lead to an estimated $2.8 \%$ reduction in yield (based on estimates by Weisz et al. [2011]), Feekes 8 and 10 applications of Prosaro and Headline will still likely be much more profitable than Feekes 5 applications. For instance, if the yield response to the PFULL10 program (244.60 kg ha-1) is reduced by $2.8 \%$ to $237.75 \mathrm{~kg} \mathrm{ha}^{-1}$ to account for the effect of wheel tracks, the probability of a profitable response at an application cost of $\$ 37.07 \mathrm{ha}^{-1}$ and grain price of $\$ 0.257 \mathrm{~kg}^{-1}, 0.70$, will still be higher than the probabilities of profitability with the PFULL5 and HFULL5 programs of 0.32 and 0.36 , respectively.

For some fungicide programs evaluated in this study, there was evidence of baseline LB severity effect of yield response and, consequently, the probability of profitability. For instance, for the PFULL8 program, the probability of profitability at a total application cost of $\$ 37.07 \mathrm{ha}^{-1}$ and grain price of $\$ 0.257 \mathrm{~kg}^{-1}$ was 0.73 when LB severity was high (flag leaves were affected) compared with only 0.12 when LB severity was low (lesions restricted to leaves below the flag leaf). Similar results were observed for PFULL5 and HHLF5+8, the other programs for which the effect of baseline LB on the yield response was significant. These findings are consisted with those of Weisz et al. (2011), based on research conducted on SRWW in the Mid-Atlantic region, and provide further support for the conclusion drawn by Weisz et al. (2011) that plant-health applications (when the risk of disease or actual disease levels are low) in SRWW are less likely to be profitable than applications based on disease risk.

Our results showed that, even with more modern fungicides and high-yielding wheat cultivars, fungicide applications before Feekes 8 were not generally effective at reducing flag leaf disease severity or increasing grain yield. Of the fungicide programs evaluated, early applications were the least likely to be profitable. Our results also showed that, for both Headline and Prosaro, split half-rate applications at Feekes 5 and 8 were just as effective as full-rate applications at Feekes 8 or 10. Based on these results, one may conclude that it was the Feekes 8 application that led to the disease and yield responses, and hypothesize that a single application of Headline or Prosaro at half the recommended rate at Feekes 8 may be just as effective as a full-rate application. In addition, because only half the recommended fungicide will be needed, one may further hypothesize that such a program will likely be more economically beneficial (profitable) than the single full-rate application programs. However, further research is needed to test these hypotheses. Moreover, the issue of fungicide resistance becomes a concern with half- or reducedrate fungicide programs, because conventional wisdom and older literature suggest that reduced rates could indeed lead to increased frequency of resistance isolates in pathogen populations (Steva 1994). However, more recent reviews of the literature indicate that selection for fungicide-resistant isolates increases with increasing dose (rate) of the fungicide (Hobbelen et al. 2014; van den Bosch and Gilligan 2008; van den Bosch et al. 2011). These recent references do argue that the number of rigorous studies on this topic is limited. Thus, the debate as to whether fungicide resistance will develop faster if lower doses of fungicides are used is far from being over. Based on our results, Feekes 8 and 10 would be the recommended timing for foliar disease management with Headline or Prosaro but, even when using these programs, baseline disease levels, grain price, and fungicide cost should be used to help guide application decisions. Knowing fungicide application costs and (projected) grain prices, producers and crop advisors will be able to use results from this study, particularly the graphs in Figs. 4 and 5, to estimate the probability of a given fungicide program being profitable before making an application.

\section{Acknowledgments}

Funding for this research was provided by USDA-NIFA Award Number 200934103-19866 for the project, entitled "Improving Disease Management in Wheat Through Novel Disease and Economic Threshold Models". Salaries and research support for K. T. Willyerd, P. A. Paul, and L. V. Madden were provided by state and federal funds to the Ohio Agricultural Research and Development Center. We thank M. Wallhead, W. Bardall, R. Barry, J. Heller, and J. Salgado for assisting with establishment, maintenance, and harvest of research plots, and treatment application in Ohio; K. Ames and J. Weems for assisting with establishment, maintenance, and harvest of research plots, and treatment application in Illinois; N. Anderson, G. Buechley, D. Nowaskie, J. Ravellette, and D. Teska for field and laboratory assistance in Indiana; and members of both the Esker and Conley programs for their assistance with establishment, maintenance, data collection, and harvest of research plots in Wisconsin.

\section{Literature Cited}

Barker, D., Beuerlein, J., Dorrance, A., Eckert, D., Eisley, B., Hammond, R., Lentz, E., Lipps, P., Loux, M., Mullen, R., Sulc, M., Thomison, P., and Watson, M. 2005. Ohio Agronomy Guide, 14th ed. The Ohio State Univ. Bull. 472.

Bergstrom, G. C. 2010. Stagonospora nodorum blotch and Stagonospora avenae blotch. Pages 75-77 in: Compendium of Wheat Diseases and Pests. W. W. Bockus, R. L. Bowden, R. M. Hunger, W. L. Morrill, T. D. Murray, and R. W. Smiley, eds. American Phytopathological Society, St. Paul, MN

Beuerlein, J., Minyo, R., Jr., Geyer, A., Paul, P., Sneller, C., and Lohnes, D. 2010 2010 Ohio wheat performance test. Horticulture and Crop Science Series 228 Ohio Agricultural Research and Development Center/Ohio State University Extension, Wooster.

Bhathal, J. S., Loughman, R., and Speijers, J. 2003. Yield reduction in wheat in relation to leaf disease from Yellow (tan) spot and Septoria nodorum blotch. Eur. J. Plant Pathol. 109:435-443.

Borenstein, M., Hedges, L. V., Higgins, J. P. T., and Rothstein, H. R. 2009 Introduction to Meta-Analysis. John Wiley \& Sons, Chichester, UK.

Bowden, R. L. 1995. Wheat foliar fungicides. Kansas State Univ. Coop. Ext. Serv. Bull. MF-1026.

Brunner, E., Domhof, S., and Langer, F. 2002. Nonparametric Analysis of Longitudinal Data in Factorial Experiments. John Wiley \& Sons, New York.

Conley, S., Roth, A., Gaska, J., and Smith, D. 2014. Wisconsin Winter Wheat Performance Tests 2014. Univ. Wisc. Ext. Publ. A3868. Online publication. http://www.coolbean.info/library/documents/A3868_WisconsinWinterWheat Trials_2014_web.pdf

Engle, J. S., Madden, L. V., and Lipps, P. E. 2006. Distribution and pathogenic characterization of Pyrenophora tritici-repentis and Stagonospora nodorum in Ohio. Phytopathology 96:1355-1362.

Gao, X. 2007. A nonparametric procedure for the two-factor mixed model with missing data. Biom. J. 49:774-788.

Gbur, E. E., McCarter, K. S., Durham, S., Young, L. J., Christman, M., West, M., and Kramer, M. 2012. Analysis of Generalized Linear Mixed Models in the 
Agricultural and Natural Resource Sciences. American Society of Agronomy, Soil Science Society of America, Crop Science Society of America, Madison, WI.

Grossmann, K., Kwiatkowski, J., and Casper, G. 1999. Regulation of phytohormone levels, leaf senescence and transpiration by the strobilurin kresoxim-methyl in wheat (Triticum aestivum). J. Plant Physiol. 154:805-808

Gurung, S., Hansen, J. M., Bonman, J. M., Gironella, A. I. N., and Adhikari, T. B. 2012. Multiple disease resistance to four leaf spot diseases in winter wheat accessions from the USDA National Small Grains Collection. Crop Sci. 52: 1640-1650.

Heger, M., Oerke, E.-C., Dehne, H.-W., and Hindorf, H. 2003. Evaluation of an action threshold-based IPM wheat model in Rheinland (Germany) in 1999/2001. Bull. OEPP/EPPO Bull. 33:397-401.

Hershman, D., Kennedy, B., and Yielding, T. 2011. Evaluation of fungicides for control of foliar diseases and Fusarium head blight of winter wheat in Kentucky, 2010. Plant Dis. Manage. Rep. 5:CF012. Online publication. http://www.plantmanagementnetwork.org/pub/trial/pdmr/volume5/abstracts/ cf012.asp

Hobbelen, P. H. F., Paveley, N. D., and van den Bosch, F. 2014. The emergence of resistance to fungicides. PLoS One 9:e91910.

Lackermann, K. V., Conley, S. P., Gaska, J. M., Martinka, M. J., and Esker, P. D. 2011. Effect of location, cultivar, and diseases on grain yield of soft red winter wheat in Wisconsin. Plant Dis. 95:1401-1406.

Large, E. C. 1954. Growth stage in cereals, illustrations of the Feekes' scale. Plant Pathol. 3:128-129.

Lipps, P. E., and Madden, L. V. 1989. Assessment of methods of determining powdery mildew severity in relation to grain yield of winter wheat cultivars in Ohio. Phytopathology 79:462-470.

Littell, R. C., Milliken, G. A., Stroup, W. W., Wolfinger, R. D., and Schabenberger, O. 2006. SAS for Mixed Models, 2nd ed. SAS Institute, Cary, NC.

Lopez, J. A., Rojas, K., and Swart, J. 2015. The economics of foliar fungicide applications in winter wheat in Northeast Texas. Crop Prot. 67:35-42.

Lupton, F. G. H. 1972. Further experiments on photosynthesis and translocation in wheat. Ann. Appl. Biol. 71:69-79.

Madden, L. V., and Paul, P. A. 2011. Meta-analysis for evidence synthesis in plant pathology: An overview. Phytopathology 101:16-30.

Mansfield, C., and Hawkins, S. 1992. Agronomy Guide-Wheat Production and Fertilization in Indiana. Purdue Univ. Ext. Bull. AY-244. West Lafayette, IN.

Marroni, M. V., Viljanen-Rollinson, S. L. H., Butler, R. C., and Deng, Y. 2006. Fungicide timing for the control of Septoria tritici blotch of wheat. N. Z. Plant Prot. 59:160-165.

McMullen, M. P. 2010. Tan Spot (Yellow Leaf Spot). Pages 82-84 in: Compendium of Wheat Diseases and Pests. W. W. Bockus, R. L. Bowden, R. M. Hunger, W. L. Morrill, T. D. Murray, and R. W. Smiley, eds. American Phytopathological Society, St. Paul, MN

Milus, E. A., and Chalkley, D. B. 1997. Effect of previous crop, seedborne inoculum, and fungicides on development of Stagonospora blotch. Plant Dis. 81:1279-1283.

Mueller, D. S., and Bradley, C. A. 2008. Field crop fungicides for the north central United States. North Central Integrated Pest Management Center. Online publication. www.ncipmc.org/action/Fungicide\%20Manual4.pdf

Nafziger, E., ed. 2009. Illinois Agronomy Handbook, 24th ed. University of Illinois Extension, Urbana.

Paul, P., Beuerlein, J., Loux, M., Lentz, E., Hammond, R., and Mullen, R. 2008a. Improving wheat profits in Ohio. The Ohio State Univ. Bull. 938.

Paul, P. A., Lipps, P. E., Hershman, D. E., McMullen, M. P., Draper, M. A., and Madden, L. V. 2008b. Efficacy of triazole-based fungicides for Fusarium head blight and deoxynivalenol control in wheat: A multivariate meta-analysis. Phytopathology 98:999-1011.

Paul, P. A., and Madden, L. V. 2014. Meta-analysis in plant disease epidemiology. In: Exercises in Plant Disease Epidemiology. K. L. Stevenson and M. J. Jeger, eds. American Phytopathological Society, St. Paul, MN

Paul, P. A., Madden, L. V., Bradley, C. A., Robertson, A. E., Munkvold, G. P., Shaner, G., Wise, K. A., Malvick, D. K., Allen, T. W., Grybauskas, A., Vincelli, P., and Esker, P. 2011. Meta-analysis of yield response of hybrid field corn to foliar fungicides in the U.S. Corn Belt. Phytopathology 101:1122-1132.

Paul, P. A., McMullen, M. P., Hershman, D. E., and Madden, L. V. 2010. Metaanalysis of the effects of triazole-based fungicides on wheat yield and test weight as influenced by Fusarium head blight intensity. Phytopathology 100 160-171.

Paveley, N. D., Lockley, K. D., Sylvester-Bradley, R., and Thomas, J. 1997. Determinants of fungicide spray decisions. Pestic. Sci. 49:379-388.

Pepler, S., Gooding, M. J., Ford, K. E., and Ellis, R. H. 2005. A temporal limit to the association between flag leaf life extension by fungicides and wheat yields. Eur. J. Agron. 22:363-373.

Ransom, J. K., and McMullen, M. V. 2008. Yield and disease control on hard winter wheat cultivars with foliar fungicides. Agron. J. 100:1130-1137.

Rideout, S. L., and Waldenmaier, C. M. 2012. Evaluation of a single early application of selected fungicides for the management of foliar disease in wheat, 2011. Plant Dis. Manage. Rep. 6:CF035. Online publication. http://www. plantmanagementnetwork.org/pub/trial/pdmr/volume6/abstracts/cf035.asp

Ruske, R. E., Gooding, M. J., and Jones, S. A. 2003. The effects of adding picoxystrobin, azoxystrobin and nitrogen to a triazole programme on disease control, flag leaf senescence, yield and grain quality of winter wheat. Crop Prot. 22:975-987.

Shah, D. A., and Bergstrom, G. C. 2000. Temperature dependent seed transmission of Stagonospora nodorum in wheat. Eur. J. Plant Pathol. 106:837-842.

Shah, D. A., and Madden, L. V. 2004. Nonparametric analysis of ordinal data in designed factorial experiments. Phytopathology 94:33-43.

Shaner, G. 2010. Septoria tritici blotch. Pages 56-58 in: Compendium of Wheat Diseases and Pests. W. W. Bockus, R. L. Bowden, R. M. Hunger, W. L. Morrill, T. D. Murray, and R. W. Smiley, eds. American Phytopathological Society, St. Paul, MN.

Shaner, G., and Buechley, G. 1995. Epidemiology of leaf blotch of soft red winter wheat caused by Septoria tritici and Stagonospora nodorum. Plant Dis. 79:928-938

Simpson, G. M. 1968. Association between grain yield per plant and photosynthetic area above the flag leaf node in wheat. Can. J. Plant Sci. 48:253-260.

Singh, P. K., Mergoum, M., Ali, S., Adhikari, T. B., Elias, E. M., and Hughes, G. R. 2006. Identification of new sources of resistance to tan spot, Stagonospora nodorum blotch, and Septoria tritici blotch of wheat. Crop Sci. 46:2047-2053.

Steva, H. 1994. Evaluating anti-resistance strategies for control of Uncinula necator. Pages 59-66 in: Fungicide Resistance. Br. Crop Prot. Counc. Monogr. No. 60. S. Heaney, D. Slawson, D. W. Hollomon, M. Smith, P. E. Russell, and D. W. Parry, eds.

Stroup, W. W. 2013. Generalized Linear Mixed Models: Modern Concepts, Methods and Applications, Chapman \& Hall/CRC Texts in Statistical Science. CRC Press, Boca Raton, FL.

Thompson, N. M., Epplin, F. M., Edwards, J. T., and Hunger, R. M. 2014 Economics of foliar fungicides for hard red winter wheat in the USA southern Great Plains. Crop Prot. 59:1-6.

van den Bosch, F., and Gilligan, C. A. 2008. Models of fungicide resistance dynamics. Annu. Rev. Phytopathol. 46:123-147.

van den Bosch, F., Paveley, N., Shaw, M., Hobbelen, P., and Oliver, R. 2011. The dose rate debate: Does the risk of fungicide resistance increase or decrease with dose? Plant Pathol. 60:597-606.

van Houwelingen, H. C., Arends, L. R., and Stijnen, T. 2002. Advanced methods in meta-analysis: Multivariate approach and meta-regression. Stat. Med. 21: 589-624.

Waxman, K. D., and Bergstrom, G. C. 2010. Evaluation of foliar fungicides for control of foliar diseases and Fusarium head blight of winter wheat in New York, 2009. Plant Dis. Manage. Rep. 4:CF017. Online publication.

Wegulo, S., Stevens, J., Zwingman, M., and Baenziger, P. S. 2012. Yield response to foliar fungicide application in winter wheat. Pages 227-244 in: Fungicides for Plant and Animal Diseases. Online publication. http://cdn.intechopen.com/pdfswm/26031.pdf

Weisz, R., Cowger, C., Ambrose, G., and Gardner, A. 2011. Multiple mid-Atlantic field experiments show no economic benefit to fungicide application when fungal disease is absent in winter wheat. Phytopathology 101:323-333.

Wiersma, J. J., Dai, J., Dahlen, R. B. A., Dill-Macky, R. 2012. Control of leaf spotting diseases and Fusarium head blight of wheat in Minnesota, 2010. Plant Dis. Manage. Rep. 6:CF039. Online publication. http://www. plantmanagementnetwork.org/pub/trial/PDMR/volume6/abstracts/CF039.asp

Wu, Y. X., and von Tiedemann, A. 2001. Physiological effects of azoxystrobin and epoxiconazole on senescence and the oxidative status of wheat. Pestic. Biochem. Physiol. 71:1-10. 